\title{
Training Strategies for Practical Ability of College Students Majoring in Computer-Aided Design
}

\author{
https://doi.org/10.3991/ijet.v15i16.15935 \\ Xingde Liu \\ Jilin Institute of Chemical Technology, Jilin, China \\ 396803006@gq. com
}

\begin{abstract}
Currently, the college students majoring in computer-aided design (CAD), a discipline under the department of mechanical engineering, generally have a poor ability to solve engineering problems. Therefore, this paper attempts to design effective training strategies to improve the practical ability of the CAD majors. Firstly, the authors highlighted the promoting effect of the CAD on the practical ability of college students, and summed up the problems of college students in the engineering application of the CAD. On this basis, several strategies were put forward to improve the practical ability of the CAD majors from three aspects: CAD curriculum planning, CAD practical training and CAD platform construction. To verify the effectiveness of the strategies, an index system was established based on information entropy, and organized into an evaluation model through expert scoring. The strategies and evaluation model provide strong supports to the training of practical ability for the CAD majors.
\end{abstract}

Keywords-Practical ability, computer-aided design (CAD), mechanical engineering, strategies, evaluation model.

\section{Introduction}

The engineering practical ability of college students is the main manifestation of the comprehensive ability, which plays a very important role in the development of their professional qualities and innovation. The training of college students' practical ability in engineering has gradually attracted more attention of the society, and become key part of the comprehensive quality training process [1-3]. CAD technology provides the supports for engineering designers to develop and design engineering products with high quality and efficiency. It has an important promoting effect on training high-level engineering technical talents. So, it occupies a very important position in the current training process of engineering practical ability of college students [4-5]. More and more attention has been paid on how to cultivate and improve the engineering practical ability of college students by the scholars, especially in the field of CAD. For example, Alves et al. used the social network-based educational model and learning factory platform and proposed an experiential learning model for acquiring CAD system interoperability skills [6]. Dasgupta et al. studied the role of 
CAD learning environment in improving integrated STEM learning in order to promote the concept of combining the seamless learning with scientific inquiry, engineering design, mathematical reasoning and technical skills [7]. Gül took the Canadian International Development Agency's 2014 Student Learning Expectations as the research object, analyzed the teaching methods of CAD courses through student questionnaires, and discussed the application in interior architecture teaching [8]. Chen et al. explored how to build a computer-aided industrial design course with the aim of training engineering practical ability [9]. Zhang et al. probe deep into how to improve the engineering practical ability of college students in the CAD course teaching reform of environmental engineering [10]. Zhao et al. studied the ways to improve college students' engineering practical ability from the perspective of PCB computeraided design for the training requirements of new engineering talents [11].

The studies above have shown that the training of practical ability of college students majoring in $\mathrm{CAD}$ of mechanical engineering is constrained by a variety of factors and conditions. Researchers have carried out relevant research and analysis from different levels and links. But due to different analysis perspectives, they have different understanding and focus on training strategies and models of college students' practical ability, which limits their research on the training and requires further systematic discussion. In view of the above, this paper further analyzes the training strategy of practical ability of college students majoring in CAD of mechanical engineering, and proposes an evaluation model based on entropy weight [12-13] and fuzzy theory [14-15]. It consists of 6 parts in total. The first part summarizes and analyzes the practical ability of CAD majors in colleges; The second part analyzes the role of CAD in promoting college students' practical ability; the third part explores the problems existing in the training process of CAD practical ability in colleges; the fourth part puts forward the training strategies for the practical ability of CAD majors; the fifth part discusses the evaluation mechanism of their practical ability; the sixth part gives the conclusion.

\section{Promoting Effects of CAD on the Practical Ability of College Students}

\subsection{Essential design technology for modern senior engineering talents}

Following the rapid development of modern science and technology, the application of engineering technology requires higher levels of intelligence. Thus, modern senior engineering talents must master certain professional intelligent design technology, while the higher-level intelligent design is more conducive to improving their design capabilities. As a key part of modern intelligent design technology, CAD technology has become an indispensable design technology for modern senior engineering talents, which plays a very important role in promoting their subsequent development. 


\subsection{Improving engineering product design quality and design efficiency}

CAD technology has changed the traditional design model of engineering products, from the original manual drawing to computer drawing, and from the original twodimensional model to a three-dimensional model. It can also realize automatic annotation and compilation of product design. Especially with the emergence of some typical CAD design software, the design errors of engineering products have been reduced, the product design accuracy and optimized design capabilities have been continuously improved, and the design cycle has also been continuously shortened. This has improved the quality and efficiency of modern product engineering design dramatically.

\subsection{Facilitating information sharing and unified design standards in engineering design}

Along with the continuous development of computer technology, network technology and information technology, modern product mostly uses the collaborative design based on digital models. An engineering design task often requires the joint efforts of multiple design units, design teams and designers. The sharing of unified standards of design information or design knowledge in the design process has become the key content in intelligent design. CAD technology offers unified modeling standards and implementation guidelines, and provides good supports for information sharing and uniform design standards in engineering design, especially with the modern intelligent technology.

\subsection{Helping realizing standardization, serialization and generalization of engineering design}

The three design forms of engineering design refer to standardization, serialization and generalization. They are also the mainstream forms of product design at present. CAD technology can provide technical support in terms of feature library, standard parts library, model library, graphics library, case library, knowledge base, parametric design, modular design, and model-based design, etc. for standardization, serialization and generalized design. It plays an indispensable role in realizing the three design forms of engineering design.

\subsection{Enhancing the integration with other intelligent engineering technologies}

Modern product engineering design is not only a high-intelligence technology implementation system, but also a decision analysis system with a high degree of integration in various design links. A perfect engineering design model needs the integration of the entire life cycle information of product design. It can be seen that the CAD mainly focuses on the use of computers to realize the structural design, variant design and modular design of products, while Computer Aided Manufacture (CAM) mainly focuses on the use of computers to realize the various design links of product pro- 
cessing and manufacturing, Computer Aided Engineering (CAE, which mainly on the use of computers to implement the various design links of product engineering calculation and analysis), and Computer Aided Process Planning (CAPP) mainly on the realization of various design links such as product process route planning, process design, processing method selection) etc. They belong to different technical support modules for product integrated design, but they still have a very close relationship of technical integration.

\section{The Current Development Situation of CAD Majors' Practical Ability in Colleges}

\subsection{The weak faculty of CAD engineering practice}

The weak faculty of CAD practice is reflected in many aspects, such as the lack of $\mathrm{CAD}$ engineering practice funds, the insufficient number of instructors, the poor construction of laboratories or practice bases, etc. In particular, some universities often have low capacity of CAD engineering practice, that is, the increase in college enrollment leads to more students participating in CAD practice. Under the limited condition of instructors and resources, sometimes a tutor needs to guide dozens or even hundreds of students in engineering practice, or many students do not have enough study time to enter the CAD laboratory for study, resulting in low efficiency in the students' CAD learning course.

\subsection{Disconnection between CAD theoretical course}

The current CAD courses in colleges mainly focuses on theoretical courses such as engineering graphics, computer graphics, and product modeling, etc., but not on the CAD-based product design specification formulation, standard formulation, and design principles, etc. in the engineering design. Many students cannot even perform basic annotation and three-view settings in CAD drawings etc. after completing the CAD theory course, which is far from meeting the technical requirements of engineering product design. This shows that the setting of CAD theoretical courses has problems such as unclear goals and inaccurate positioning, and disconnection from engineering practice.

\subsection{The backward CAD practice model}

Due to the relatively low level of faculty in some universities and the limitation in the investment of discipline construction funds, CAD practical teaching contents, CAD practice methods, and CAD practice concepts have not changed for a few years or even decades in the implementing process of CAD practical courses. Especially with the continuous development of artificial intelligence such as computer technology and network technology, many CAD practice contents and methods have been 
gradually eliminated, and lots of practice contents often become a form, deviating from engineering practice.

\subsection{Inadequate implementation of $\mathrm{CAD}$ engineering practice}

The inadequate implementation of CAD engineering practice is mainly reflected in two aspects: first, the curriculum system of CAD engineering practice is fragmented, the practical courses are not closely correlated, and they often only focus on the training of local links, but ignoring the entirety of the practice courses; second, the duration of CAD engineering practice courses is generally short, indicating a weak sustainability and continuity.

\subsection{The difficulty of CAD engineering practice in meeting social needs}

The CAD engineering practice curriculums in many colleges are generally set up in the processing center of the school, or the mechanical equipment enterprises. Students are not completely involved in the application practice of CAD technology, and the $\mathrm{CAD}$ engineering practice established in colleges does not really achieve the mode of school-enterprise cooperation or the mode of integration of industry, university and research, so that it is often inconsistent with the needs of society. Moreover, due to the unreasonable curriculum planning, college students are not interested in CAD practice, and do not care about whether they meet social needs. But considering the academic credits, they have to participate in the practice. This makes it difficult for the $\mathrm{CAD}$ engineering practice to meet the predetermined requirements.

\subsection{Insufficient innovation in CAD engineering practice}

The current CAD engineering practice in colleges often has a fixed practice process and framework, which solidifies the thinking of CAD engineering practice. Plus, the CAD application technology in the CAD engineering practice is lagging behind, failing to show the innovation of engineering practice. In addition, due to the lack of engineering background or engineering research experience in many colleges, CAD practice instructors also feel it difficult to innovate in engineering practice during the college students' CAD engineering practice.

\section{$4 \quad$ Training Strategies for Practical Ability of College Students Majoring in CAD}

In view of the above, the authors proposed to improve the practical ability of the CAD majors from three aspects: CAD curriculum planning, CAD practical training, and $\mathrm{CAD}$ platform construction. 


\subsection{CAD curriculum planning}

The CAD curriculum planning is the primary condition for training the practice ability of college students majoring in CAD. The planning of CAD curriculums need to be in line with the training objectives of practice ability. Based on this, the key parts of CAD courses should be fulfilled well, including the division of CAD course types, the formulation of CAD course tasks, selection of CAD course materials, $\mathrm{CAD}$ teaching planning, selection of CAD course contents for teaching students, and selection of teaching time. In general, the types of CAD courses include CAD theory courses, CAD experiment courses, CAD skill training courses, CAD professional practice courses, academic reports in CAD-related fields, and lectures by famous teachers. For these types of CAD courses, the corresponding tasks vary. CAD theory courses, academic reports, lectures by famous teachers, etc. generally focus on the cultivation of professional basic knowledge or the expansion of professional perspectives; CAD experiment courses, CAD skill training courses, and CAD professional practice course generally emphasize on the integration of professional theoretical knowledge and professional engineering practice. It can be seen that the different tasks of CAD courses will lead to differences in the selection of teaching materials and the planning of course teaching plans. For the training courses emphasizing students' professional basic knowledge, the selected textbooks and programs need to highlight professional knowledge points, frameworks and levels; for those that focus on students' professional engineering practice and knowledge fusion, the selected textbooks and planning schemes need to highlight how professional knowledge is effectively transformed into engineering practice results, including modes, methods, effects of transformation, etc. In addition, according to the students' knowledge level and acceptance ability, it is necessary to consider which grades of college students need to be taught for specific courses, and at what time period the courses are taught. All these factors will affect the students' cognition and absorptive ability of CAD courses, and further the training of students' practical ability.

\subsection{CAD practical training}

The CAD practical training is performed in the forms of course production practice, graduation internships, scientific and technological competitions, scientific research projects and activities, curriculum design, graduation design and so on. These forms have difference focuses of research, and the goals and requirements for training students' practical ability also vary. The production practice of CAD courses requires college students to combine internship tasks in the learning process and participate in practice as an engineering technician. It's a form of teaching that combines professional knowledge with production practice. Graduation internships require them to complete all the courses before graduation. Then, they perform production internships using the professional knowledge learned according to the graduation design tasks, and prepare for graduation thesis. This focuses on training students' ability to solve engineering problems independently. Scientific and technological competitions more emphasize the cultivation of students' innovative ability in engineering practice. It 
needs college students to combine specific CAD design topics and complete the design of engineering products with specific design goals, design conditions or design constraints. Scientific research projects and activities require students to be able to integrate into or participate in the scientific research projects of instructors, and complete scientific research tasks in accordance with specific CAD technical requirements, which has an important role in promoting the students' independent scientific research capabilities. Curriculum design is mainly to examine the comprehensive application ability of the CAD course knowledge learned after completing the current CAD course teaching, and to strengthen and deepen the knowledge points of the CAD course learned earlier. Graduation design is an assessment of students' comprehensive ability. Students need to conduct engineering product design and research based on selected CAD design topics. Generally, they need to complete many aspects of product scheme design, calculation analysis, engineering drawing, process planning and market demonstration, and finally form a graduation design report.

\subsection{CAD platform construction}

Both the CAD curriculum planning and CAD practical training need to rely on the construction of a good CAD engineering practice platform. The CAD construction platform provides an application support platform for college students' engineering practice. On the one hand, under the support of advanced intelligent technology, this platform improves the practical training efficiency of CAD courses; on the other hand, the support of a high-level technical platform can ensure the full integration of CAD course theory and practice, providing students with more practice opportunities, time and content. It is conducive to the training of practical ability of CAD majors. The authors believe that the construction of CAD practice platform needs to be prepared in the following aspects, namely CAD software and hardware system configuration (including faculty, hardware facilities, laboratory configuration), teaching platform construction, school-enterprise cooperation platform construction, engineering practice center construction, engineering application base construction, key laboratory construction, industry-university-research platform construction, science and technology innovation platform construction, etc. The above platform construction tasks can be divided into three parts: one is the CAD course teaching-oriented platform construction, such as CAD software and hardware system configuration and teaching platform construction, etc., mainly to provide support for the smooth implementation of $\mathrm{CAD}$ course teaching; the second is CAD engineering practice-oriented platform construction, such as the construction of a school-enterprise cooperation platform, an engineering practice center, an engineering application base, and key laboratories, etc., mainly to provide students with an application platform for CAD engineering practice; the third is the $\mathrm{CAD}$ engineering innovation-oriented platform construction, such as the construction of industry-university-research platforms and the construction of technological innovation platforms, etc., mainly to provide students with application platforms for CAD engineering innovation and engineering technology deepening. 


\section{$5 \quad$ Analysis for the Evaluation Mechanism of CAD Majors' Practical Ability}

\subsection{Selection of evaluation index}

The training effect of CAD majors' practical ability in colleges needs to be verified intuitively through specific evaluation results, that is, on the basis of selecting the evaluation index, focus should be on evaluating the engineering practice effect of CAD majors. The authors believe that the evaluation of practical ability training for CAD majors should emphasize on seven aspects: the basic CAD theoretical knowledge of students, CAD engineering practice skills, CAD innovation ability, the integration of $\mathrm{CAD}$ professional theory and engineering practice, the self-learning ability, the social satisfaction and the achievement of CAD practical training.

\subsection{Evaluation index weight processing}

This paper applies the information entropy [16-20] to analyze the evaluation index weight of the engineering practical ability of college students majoring in CAD.

Experts in the CAD field were invited to score the evaluation indicators according to the unified evaluation criteria. Assuming that there are $m$ experts and $n$ evaluation indicators, and the $i$-th expert give a score of $s_{i j}$ to the $j$-th evaluation indicator, then it forms an evaluation matrix $S$ for practical ability training of CAD majors, namely

$$
\mathbf{S}=\left[\begin{array}{ccccc}
s_{11} & \cdots & s_{1 j} & \cdots & s_{1 n} \\
\vdots & \cdots & \vdots & \cdots & \vdots \\
s_{i 1} & \cdots & s_{i j} & \cdots & s_{i n} \\
\vdots & \cdots & \vdots & \cdots & \vdots \\
s_{m 1} & \cdots & s_{m j} & \cdots & s_{m n}
\end{array}\right]
$$

The information entropy $e_{j}$ for the evaluation index of the $\mathrm{j}$-th CAD major is given as:

$$
e_{j}=-\sum_{i=1}^{m}\left(\left(s_{i j} / \sum_{i=1}^{m} s_{i j}\right) * \ln \left(s_{i j} / \sum_{i=1}^{m} s_{i j}\right)\right) / \ln m
$$

The absolute weight $\bar{w}_{j}$ for the evaluation index of the $j$-th CAD major is given as:

$$
w_{j}^{*}=1-E_{j}, \quad 1 \leq j \leq n
$$

The relative weight $w_{j}$ for the evaluation index of the $j$-th CAD major is given as: 


$$
w_{j}=\frac{\bar{w}_{j}}{\sum_{j=1}^{n} \bar{w}_{j}}=\frac{\left(1-e_{j}\right)}{\sum_{j=1}^{n}\left(1-e_{j}\right)}
$$

It can be seen that the relative weight $w_{j}$ meets $0 \leq w_{j} \leq 1, \sum_{j=1}^{n} w_{j}=1$. Thus, the weight sequence $\boldsymbol{W}$ of all evaluation indicators can be obtained, namely

$$
\mathbf{W}=\left(w_{1}, \cdots, w_{j}, \cdots, w_{n}\right)
$$

\subsection{Implementation of evaluation methods}

Different evaluation indicators of students' practical ability will generally have different types and dimensions. To maintain a uniform scale of the evaluation results, all indicators were standardized. From a general perspective, assuming that the value of the $j$-th evaluation index of the $i$-th evaluation object is $v_{i j}=\left[v_{i j}^{a}, v_{i j}^{b}\right], v_{i j}^{a} \leq v_{i j}^{b}$, then the standardized value of the $j$-th evaluation index is $u_{i j}=\left[u_{i j}^{a}, u_{i j}^{b}\right], u_{i j}^{a} \leq u_{i j}^{b}$.

If the $j$-th evaluation indicator is a positive indicator, i.e., the bigger, the better. Then, there is

$$
\left\{\begin{array}{l}
u_{i j}^{a}=\frac{v_{i j}^{a}-\min _{1 \leq i \leq p}\left(r_{i j}^{l e f}\right)}{\max _{1 \leq i \leq p}\left(v_{i j}^{b}\right)-\min _{1 \leq i \leq p}\left(v_{i j}^{a}\right)} \\
u_{i j}^{b}=\frac{v_{i j}^{b}-\min _{1 \leq i \leq p}\left(r_{i j}^{l e f}\right)}{\max _{1 \leq i \leq p}\left(v_{i j}^{b}\right)-\min _{1 \leq i \leq p}\left(v_{i j}^{a}\right)}
\end{array}\right.
$$

$p$ indicates the number of evaluation objects.

If the $j$-th evaluation indicator is a negative indicator, i.e., the smaller, the better. Then, there is

$$
\left\{\begin{array}{l}
u_{i j}^{a}=\frac{\max _{1 \leq i \leq p}\left(v_{i j}^{b}\right)-v_{i j}^{b}}{\max _{1 \leq i \leq p}\left(v_{i j}^{b}\right)-\min _{1 \leq i \leq p}\left(v_{i j}^{a}\right)} \\
u_{i j}^{b}=\frac{\min _{1 \leq i \leq p}\left(v_{i j}^{b}\right)-v_{i j}^{a}}{\max _{1 \leq i \leq p}\left(v_{i j}^{b}\right)-\min _{1 \leq i \leq p}\left(v_{i j}^{a}\right)}
\end{array}\right.
$$

Therefore, the ideal value interval of the $j$-th evaluation index for all evaluation objects can be formed, namely 


$$
\left\{\begin{array}{l}
u_{j}^{* a}=\max \left\{u_{i j}^{a}, \cdots, u_{i j}^{a}, \cdots, u_{m j}^{a}\right\} \\
u_{j}^{* b}=\max \left\{u_{i j}^{b}, \cdots, u_{i j}^{b}, \cdots, u_{m j}^{b}\right\}
\end{array}\right.
$$

Then, the ideal value sequence $\boldsymbol{U}^{*}$ of all evaluation objects with respect to the evaluation index is given as:

$$
\mathbf{U}^{*}=\left\{u_{1}^{*}, \cdots, u_{j}^{*}, \cdots, u_{n}^{*}\right\}
$$

The fuzzy distance between the $i$-th evaluation object and $\boldsymbol{U}^{*}$ with respect ti the $j$ th evaluation index [21-25] is:

$$
D_{i j}=\sqrt[Q]{\left(\left|u_{j}^{* a}-u_{i j}^{a}\right|^{Q}+\left|u_{j}^{* b}-u_{i j}^{b}\right|^{Q}\right) / 2}
$$

In particular, at $Q=1, D_{i j}$ is the Hamming distance; at $Q=2, D_{i j}$ is the Euclidean distance.

Considering the weight $w_{j}$ of different evaluation indicators, the weighted fuzzy correlation between the $i$-th evaluation object and $\boldsymbol{U}^{*}$ with respect to all evaluation indicators is given as:

$$
\theta_{i}=\sum_{j=1}^{n}\left(w_{j} *\left(1-D_{i j}\right)\right)
$$

It's assumed that the evaluation threshold for training strategies of CAD majors' practical ability training is $\theta_{0}$. At $\theta_{i} \geq \theta_{0}$, it indicates that the training effect of the $i$ th evaluation object is satisfactory.

\section{Conclusion}

This paper first analyzes the promoting effect of the CAD on the practical ability of college students. Also, it points out the problems in the training of CAD majors' practical ability, due to various factors such as weak faculty, backward models, disconnected theory and practice, insufficient implementation, poor adaptability, and insufficient innovation. To this end, several strategies were put forward to improve the practical ability of the CAD majors from three aspects: CAD curriculum planning, CAD practical training and CAD platform construction. An index system was established based on information entropy, and organized into an evaluation model through expert scoring. The strategies and evaluation model provide strong supports to the training of practical ability for the CAD majors. This study has good innovation and application value. 


\section{$7 \quad$ Acknowledgement}

Funded project: The "13th Five-year plan" project of Jilin Education and Science in 2017: "The Research and Practice on Engineering Ability Cultivation of Applied Talents in Mechanical Field" (Project No.: GH170473); Major Teaching and Research Project of Jilin Institute of Chemical Technology in 2016: The Research and Practice on CAD Technology and Engineering Practice Ability Cultivation of Mechanical Students.

\section{$8 \quad$ References}

[1] Wang, R. D., Wang, P. L., Wang, Z. Q., Qian, Y. (2019). The exploration of engineering practice and innovation ability training mode in Application-oriented Universities. Chinese University Technology Transfer, (10): 59-62. https://doi.org/10.16209/j.cnki.cust.2019.10. $\underline{014}$

[2] Zhao, Z. H., Shen. J., Chang, H. H. (2020). Promoting the Effect of Comprehensive Practical Skill Competition on Students' Engineering Ability under the Background of Emerging Engineering. Social Sciences Journal of Universities in Shanxi, 32(1): 73-76. https://dx. doi.org/10.16396/j.cnki.sxgxsksb.2020.01.014

[3] Phillips, M., Fosmire, M., Turner, L., Petersheim, K., Lu, J. (2019). Comparing the Information Needs and Experiences of Undergraduate Students and Practicing Engineers. The Journal of Academic Librarianshipg, 45(1): 39-49. https://doi.org/10.1016/j.acalib.2018. $\underline{12.004}$

[4] Liu, M. J., Fan, S. G., Ren, C. L., Zheng, M. (2018). Investigation and Analysis of Educational Reformation for the Application of CAD and Structural Design Software in Civil Engineering. Education Modernization, 5(1): 318-321, 333. https://doi.org/ 10.16541/j.cn ki.2095-8420.2018.01.115

[5] Fei, X. (2017). The Problems and Reflections on the Cultivation of Engineering Practice Ability of Engineering Students. Education Modernization, 4(49): 42-46. https://doi.org/ 10.16541/j.cnki.2095-8420.2017.49.014

[6] Alves, C., Putnik, G. (2019). Experiential Learning of CAD Systems Interoperability in Social Network-based Education. Procedia CIRPon, 84: 209-214. https://doi.org/10.1016/j. procir.2019.07.0021

[7] Dasgupta, C., Magana, A. J., Vieira, C. (2019). Investigating the affordances of a CAD enabled learning environment for promoting integrated STEM learning. Computers \& Education, 129: 122-142. https://doi.org/10.1016/j.compedu.2018.10.014

[8] Gül, O. (2015). A Study on Instructional Methods Used in CAD Courses in Interior Architecture Education. Procedia - Social and Behavioral Sciences, 174: 1758-1763. https://doi. org/10.1016/j.sbspro.2015.01.834

[9] Chen Y., Yao, H. R., Zhou, M., Yin, Y. Y. (2020). Research on the Curriculum Construction of Computer Aided Industrial Design Oriented to Engineering Practice. Education Teaching Forum, (6): 171-172

[10] Zhang, L. P., He, X. W., Jia, J. L., Yu, Y., Zhang, K. (2014). Discussing of environmental engineering $\mathrm{CAD}$ teaching reform based on engineering practice. China Modern Educational Equipment, (19): 39-40, 45. https://doi.org/10.13492/j.cnki.cmee.2014.19.014 
[11] Zhao, Y., Wang, J., Zhang, W. J. (2019). Exploration on the Teaching Mode of PCB Computer Aided Design under the Background of New Engineering. Science \& Technology Vision, (32), 46-47. http://dx.doi.org/10.19694/j.cnki.issn2095-2457.2019.32.018

[12] Oluah, C., Akinlabi, E. T., Njoku, H. O. (2020). Selection of phase change material for improved performance of Trombe wall systems using the entropy weight and TOPSIS methodology. Energy and Buildings, 217: 1-10. https://doi.org/10.1016/j.enbuild.2020.109 967

[13] Attarakih, M., Bart, H. J., Abu-Khader, M. (2019). On the solution of the population balance equation: From global to local constrained maximum entropy method. Chemical Engineering Science, 209: 1-13. https://doi.org/10.1016/j.ces.2019.115168

[14] Song, J. H., Xie, H., Shi, L. P. (2019). Design of improved algorithm and model for multiconstrained fuzzy predictive analysis. Revue d'Intelligence Artificielle, 33: 467-473. https ://doi.org/10.18280/ria.330610

[15] Marwan, H., Ali, A. (2019). Experts' consensus to identify elements of career management competencies in Work-Based Learning (WBL) program using fuzzy delphi analysis, International Journal of Emerging Technologies in Learning, 14: 73-86. https://doi.org/10.3991/ ijet.v14i20.11461

[16] Karimian, S. F., Modarres, M., Bruck, H. A. (2020). A new method for detecting fatigue crack initiation in aluminum alloy using acoustic emission waveform information entropy. Engineering Fracture Mechanics, 223: 1-12. https://doi.org/10.1016/j.engfracmech.2019.10 $\underline{6771}$

[17] Savari, C., Sotudeh-Gharebagh, R., Kulah, G., Koksal, M., Mostoufi, N. (2019). Detecting stability of conical spouted beds based on information entropy theory. Powder Technology, 343: 185-193. https://doi.org/10.1016/j.powtec.2018.11.028

[18] Atalay, K. D., Atalay, B., Isin, F. B. (2019). FIPIA with information entropy: A new hybrid method to assess airline service quality. Journal of Air Transport Management, 76: 67-77. https://doi.org/10.1016/j.jairtraman.2019.02.004

[19] Thuy, N. N., Wongthanavasu, S. (2019). On reduction of attributes in inconsistent decision tables based on information entropies and stripped quotient sets. Expert Systems with Applications, 137: 308-323. https://doi.org/10.1016/j.eswa.2019.06.071

[20] Khorshidi, M. S., Nikoo, M. R., Taravatrooy, N., Sadegh, M., Al-wardy, M., Al-Rawas, G.A. (2020). Pressure sensor placement in water distribution networks for leak detection using a hybrid information-entropy approach. Information Sciences, 516: 56-71. https:// doi.org/10.1016/j.ins.2019.12.043

[21] Franzoi, L., Sgarro, A. (2017). Linguistic classification: T-norms, fuzzy distances and fuzzy distinguishabilities. Procedia Computer Science, 112: 1168-1177. http://doi.org/10. 1016/j.procs.2017.08.163

[22] Fernández, A., Elkano, M., Galar, M., Sanz, J.A., Alshomrani, S., Bustince, H., Herrera, F. (2016). Enhancing evolutionary fuzzy systems for multi-class problems: Distance-based relative competence weighting with truncated confidences (DRCW-TC). International Journal of Approximate Reasoning, 73: 108-122. http://doi.org/10.1016/j.ijar.2016.02.005

[23] Saini, N., Bajaj, R. K., Gandotra, N., Dwivedi, R. P. (2018). Multi-criteria Decision Making with Triangular Intuitionistic Fuzzy Number based on Distance Measure \& Parametric Entropy Approach. Procedia Computer Science, 125: 34-41. https://doi.org/ 10.1016/j.pro cs.2017.12.007

[24] Taheri, R., Ghahramani, M., Javidan, R., Shojafar, M., Pooranian, Z., Conti, M. (2020). Similarity-based Android malware detection using Hamming distance of static binary features. Future Generation Computer Systems, 105: 230-247. https://doi.org/10.1016/j.future. $\underline{2019.11 .034}$ 
[25] Djellab, M., Mehallegue, N., Achi, A. (2019). Use of Neumann series decomposition to fit the Weighted Euclidean distance and Inner product scoring models in automatic speaker recognition. Pattern Recognition Letters, 125: 500-507. https://doi.org/10.1016/j.patrec.20 $\underline{19.06 .013}$

\section{$9 \quad$ Author}

Xingde Liu, male, born on April 11, 1974, an associate professor, who is mainly engaged in teaching and scientific research of higher learning. During his tenure as a dean from 2015 to 2019, he successively organized major evaluation, major assessment and professional certification application. His research direction is CAD application technology research and non - standard equipment development.

The scientific research projects presided by him include: over 6 scientific research projects and 4 teaching and research projects. He edited 5 textbooks and works, publishing 10 papers, of which 6 is written as the first author and guided students to participate in the innovation competition, winning more than 60 awards at or above the provincial level, including 3 at the national level and 23 first prizes at the provincial level. He also guided students to be involved in 7 "mass entrepreneurship and innovation" projects, 2 at the national level and 5 at the provincial level.

Article submitted 2020-06-01. Resubmitted 2020-08-05. Final acceptance 2020-08-06. Final version published as submitted by the authors. 